Folia Cardiologica 2017

\title{
Ostre rozwarstwienie aorty u pacjenta z wieloletnim nieleczonym nadciśnieniem tętniczym oraz zespołem metabolicznym
}

\section{Acute aortic dissection in a patient with long-standing untreated hypertension and metabolic syndrome}

\author{
Małgorzata Woźniak ${ }^{1}$, Elżbieta Piechocka ${ }^{1}$, Joanna Latek-Książek ${ }^{1}$, \\ Mariusz Furmanek ${ }^{2,3}$, Robert Gil ${ }^{1,4}$, Aneta Gziut ${ }^{1}$ \\ ${ }^{1}$ Klinika Kardiologii Inwazyjnej Centralnego Szpitala Klinicznego Ministerstwa Spraw Wewnętrznych i Administracji w Warszawie \\ ${ }^{2}$ Zakład Diagnostyki Radiologicznej Centralnego Szpitala Klinicznego Ministerstwa Spraw Wewnętrznych i Administracji w Warszawie \\ ${ }^{3}$ Zakład Radiologii i Diagnostyki Obrazowej Centrum Medycznego Kształcenia Podyplomowego w Warszawie \\ ${ }^{4}$ Instytut Medycyny Doświadczalnej i Klinicznej Polskiej Akademii Nauk w Warszawie
}

\section{Streszczenie}

Ostre rozwarstwienie aorty (AOD) jest jednym z potencjalnych powikłań nieleczonego nadciśnienia tętniczego. Jego objawy, w tym silny rozrywający ból zamostkowy promieniujący do kręgosłupa, często sugerują ostry zespół wieńcowy. Podstawą diagnozy jest obraz uzyskany w tomografii komputerowej aorty. Pacjenci z AOD wymagają pilnej operacji naczyniowej. Jednym z warunków jej powodzenia i dobrego rokowania jest uzyskanie obniżenia ciśnienia tętniczego. W pracy przedstawiono przypadek pacjenta z nieleczonym wieloletnim nadciśnieniem tętniczym, u którego doszło do rozwarstwienia aorty zstępującej oraz jej odgałęzień i, w konsekwencji, do pogorszenia funkcji nerek. Po początkowych trudnościach w ustaleniu optymalnej farmakoterapii uzyskano obniżenie wartości ciśnienia tętniczego i nie obserwuje się poszerzenia wrót rozwarstwienia.

Słowa kluczowe: nadciśnienie tętnicze, dyslipidemia, ostre rozwarstwienie aorty

Folia Cardiologica 2017; 12, supl. B: B30-B33

\section{Wstęp}

Ostre rozwarstwienie aorty (AOD, acute aortic dissection) jest jednym z ostrych zespołów aortalnych [1]. W jego przebiegu dochodzi do rozerwania warstwy środkowej i oddzielenia warstw ściany aorty z wytworzeniem świateł prawdziwego i rzekomego. Stosuje się dwie klasyfikacje AOD oparte na lokalizacji - De Bakeya oraz Stanford. Najczęstszym czynnikiem ryzyka AOD jest źle kontrolowane nadciśnienie tętnicze (65-75\%).
Poniżej opisano przypadek pacjenta, u którego AOD wystąpiło jako powikłanie nieleczonego nadciśnienia tętniczego.

\section{Opis przypadku}

Mężczyzna w wieku 43 lat został przyjęty na szpitalny oddział ratunkowy z powodu trwających od kilku godzin bardzo silnych dolegliwości bólowych w klatce piersiowej, promieniujących do nadbrzusza. Dolegliwości te, poprze- 
dzone zasłabnięciem, rozpoczęły się podczas wysiłku fizycznego. U pacjenta przed 7 laty rozpoznano nadciśnienie tętnicze, ale nie przyjmował zaleconych leków. Miesiąc przed przyjęciem podczas okresowych badań profilaktycznych na podstawie podwyższonych wartości ciśnienia tętniczego (RR 160/100 mm Hg), zwiększonego obwodu talii $(101 \mathrm{~cm})$ oraz wyników badań laboratoryjnych (stężenie triglicerydów $211 \mathrm{mg} / \mathrm{dl}$, stężenie cholesterolu frakcji HDL [high-density lipoprotein] $39 \mathrm{mg} / \mathrm{dl}$, stężenie cholesterolu frakcji LDL [low-density lipoprotein] $151 \mathrm{mg} /$ dl, glikemia $100 \mathrm{mg} / \mathrm{dl}$ ) rozpoznano u niego zespół metaboliczny (wg wspólnego stanowiska ID/NHLBI/AHA/WHF/ IAS/IASO 2009) [2].

Na szpitalnym oddziale ratunkowym, spośród odchyleń w badaniu przedmiotowym, stwierdzono podwyższone RR (180/110 mm Hg), tachykardię 120/min i słabo wyczuwalne tętno nad tętnicami udowymi. W zapisie elektrokardiograficznym (EKG) nie stwierdzono cech niedokrwienia mięśnia sercowego. Badanie tomografii komputerowej (CT, computed tomography) ujawniło natomiast rozwarstwienie aorty piersiowo-brzusznej przebiegające od lewej tętnicy podobojczykowej do proksymalnych odcinków obu tętnic biodrowych zewnętrznych (typ III wg De Bakeya) (ryc. 1). Rozwarstwienie obejmowało pień trzewny, górną tętnicę krezkową oraz obie tętnice nerkowe, powodując ich odcinkowe, istotne zwężenie z niedrożnością środkowego i dalszego odcinka grzbietowej gałęzi lewej tętnicy nerkowej. Zobrazowano rozległy zawał tylnego odcinka lewej nerki oraz mniejsze zawały w prawej nerce. By obniżyć ciśnienie tętnicze, na szpitalnym oddziale ratunkowym zastosowano wlew urapidilu.

Pacjenta w trybie pilnym przyjęto do kliniki chirurgii naczyniowej. W badaniach laboratoryjnych spośród nieprawidłowości stwierdzono podwyższone parametry niewydolności nerek (stężenie kreatyniny 2,54 mg/dl, szacowany wskaźnik filtracji kłębuszkowej (eGFR, estimated glomerular filtration rate) $28 \mathrm{ml} / \mathrm{min}$, stężenie mocznika $81 \mathrm{mg} / \mathrm{dl}$ ). W trakcie 6 godzin nie uzyskano istotnego obniżenia wartości ciśnienia tętnicznego (RR > 160/95 mm $\mathrm{Hg}$ ), wobec czego zintensyfikowano leczenie hipotensyjne - odstawiono urapidil i włączono nitroglicerynę dożylnie (maks. przepływ $20 \mathrm{mg} / \mathrm{kg} \mathrm{mc}$./min), metoprolol (2 × $50 \mathrm{mg}$ ) i amlodipinę (10 mg). Ze względu na złą kontrolę ciśnienia tętniczego (średnio 150/100 mm Hg) w kolejnej dobie dołączono wlew ciągły furosemidu oraz zamieniono amlodipinę na nitrendipinę, uzyskując obniżenie RR poniżej 140/80 mm Hg i tętno 70/min. W 2. dobie hospitalizacji tuż za odejściem lewej tętnicy szyjnej implantowano do aorty piersiowej stentgraft. W kontrolnej angiografii uwidoczniono

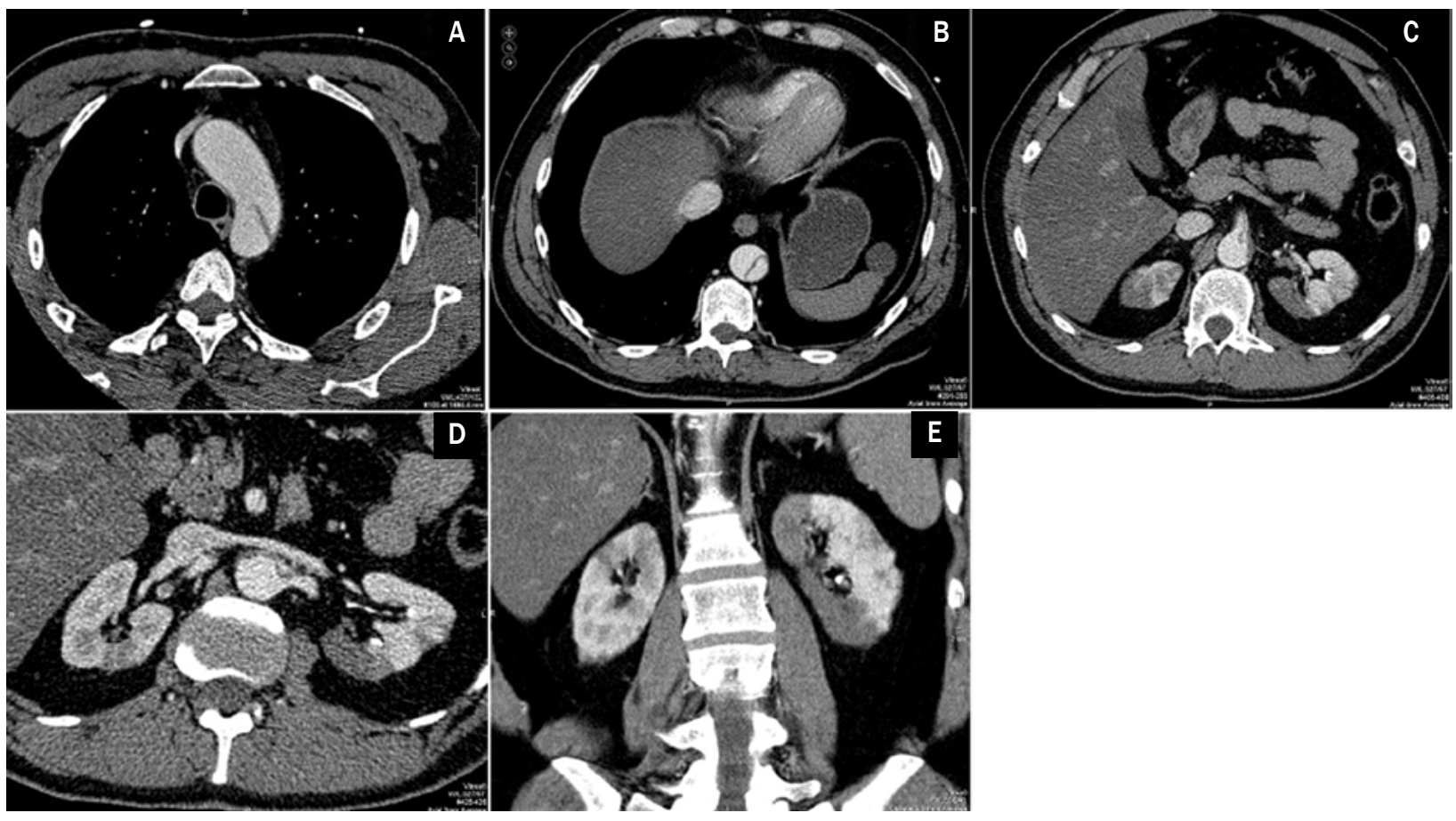

Rycina 1A-E. Badanie tomografii komputerowej po dożylnym podaniu środka kontrastowego. Rozwarstwienie aorty typu B według Stanford (III wg DeBekaya). Wrota pierwotne lokalizują się tuż za odejściem lewej tętnicy podobojczykowej (A). Kanał prawdziwy w dolnej części aorty zstępującej (B) i w aorcie brzusznej (C, D) jest mniejszy od kanału fałszywego. Rozwarstwienie sięga w obręb pnia trzewnego, górnej tętnicy krezkowej i obu tętnic nerkowych (C, D) oraz przechodzi na obie tętnice biodrowe wspólne. Brak zakontrastowania środkowego i dalszego odcinka grzbietowej gałęzi lewej tętnicy nerkowej (C) świadczy o jej zamknięciu w wyniku rozwarstwienia; następczy rozległy zawał tylnego odcinka lewej nerki (C, D, E). Mniejsze zawały widać także w prawej nerce (C, D, E) 


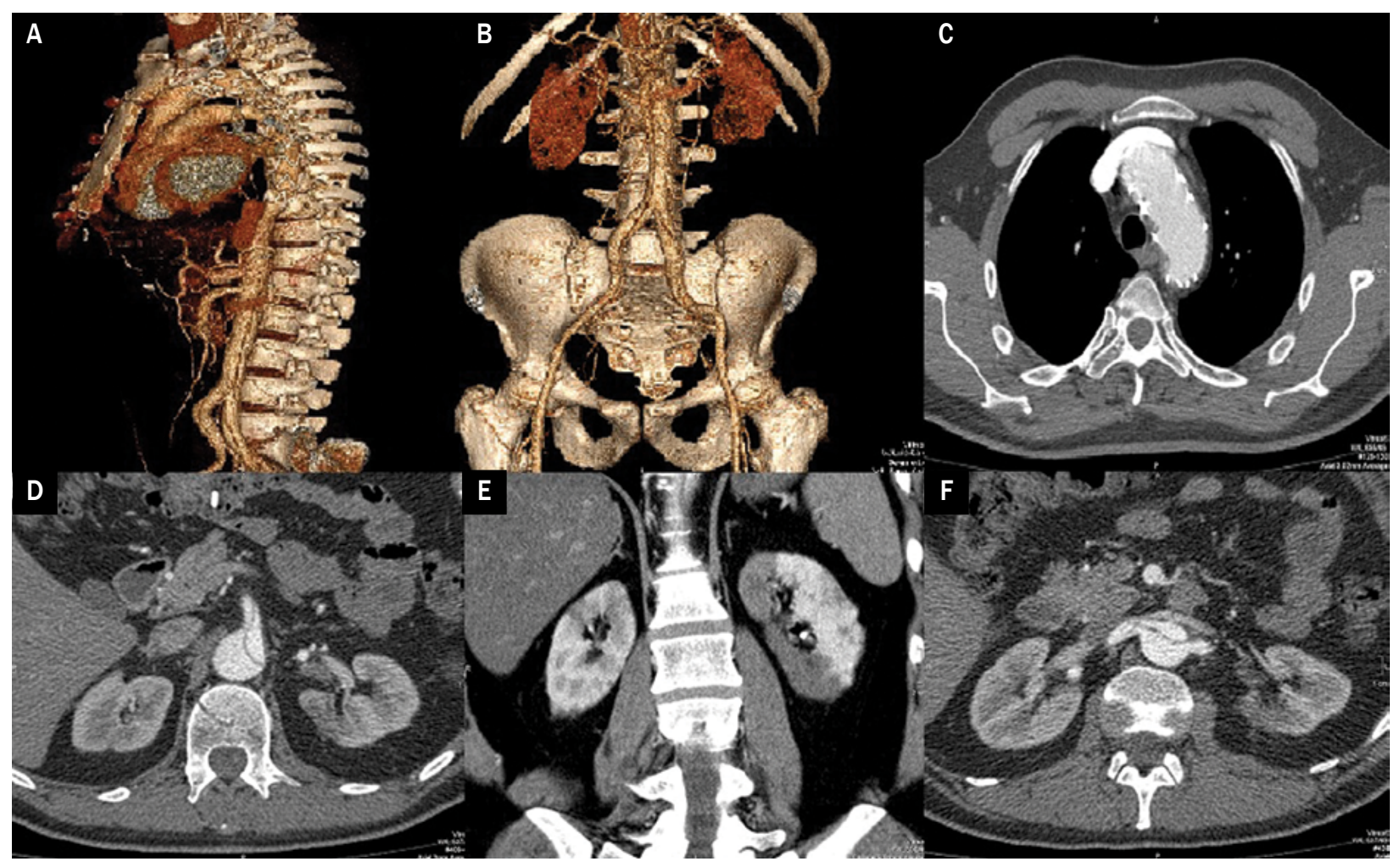

Rycina 2A-F. Kontrolne badanie angiografii tomografii komputerowej aorty. Stan po wszczepieniu stentgraftu aortalnego i skutecznym zamknięciu pierwotnych wrót rozwarstwienia, bez cech przecieku (A, C). Utrzymujące się rozwarstwienie pnia trzewnego (A, B), tętnicy krezkowej górnej (B, D, E), obu tętnic nerkowych (E, F) i obu tętnic biodrowych wspólnych (B). Niedrożna grzbietowa gałąź lewej tętnicy nerkowej (D); ewolucja zawału tylnego odcinka tożstronnej nerki (D, E, F)

prawidłowe wyłączenie kanału rozwarstwienia i prawidłowy przepływ w tętnicach łuku aorty oraz w tętnicach trzewnych i nerkowych. Uzyskano stopniową normalizację parametrów nerkowych (stężenie kreatyniny 1,17 mg/dl, wartość eGFR $68 \mathrm{ml} / \mathrm{min}$, stężenie mocznika $42 \mathrm{mg} / \mathrm{dl}$ ). W kontrolnym badaniu ultrasonograficznym (USG) zobrazowano nerki prawidłowej wielkości o zachowanej strukturze korowordzeniowej i prawidłowej grubości warstwy miąższowej; nie wykazano zaburzeń przepływu w tętnicach nerkowych (wskaźnik oporoy (RI, resistive index) w prawej nerce 0,62, w lewej $-0,57$, prawidłowe czasy akceleracji w naczyniach nerek). Po zabiegu kilkakrotnie modyfikowano leczenie hipotensyjne (odstawiono leki dożylne, dołączono walsartan, doksazosynę i klonidynę), uzyskując obniżenie wartości RR poniżej 120/80 mm Hg. Przy wypisaniu zalecono pacjentowi regularną kontrolę ciśnienia tętniczego, stosowanie diety ubogotłuszczowej, ograniczenie ilości spożywanej soli i zmniejszenie masy ciała oraz regularne przyjmowanie leków: kwasu acetylosalicylowego w dawce 75 mg, nitrendipiny w dawce 2 razy $20 \mathrm{mg}$, winianu metoprololu w dawce 2 razy $50 \mathrm{mg}$, doksazosyny w dawce 3 razy $4 \mathrm{mg}$, walsartanu w dawce 2 razy $80 \mathrm{mg}$, furosemidu w dawce 2 razy $40 \mathrm{mg}$, klonidyny w dawce 3 razy $75 \mathrm{mg}$ oraz atorwastatyny w dawce $20 \mathrm{mg}$.
Miesiąc po zabiegu u pacjenta wykonano kontrolną CT (ryc. 2). Nie uwidoczniono cech przecieku w obrębie stentgraftu; zobrazowano rozwarstwienie na całej długości poszerzonej tętniakowato w odcinku podprzeponowym aorty brzusznej, przechodzące na tętnice biodrowe wspólne i lewą tętnice biodrową zewnętrzną. Ponadto stwierdzono niedrożną gałąź grzbietową lewej tętnicy nerkowej z ewolucją zawału tylnego odcinka lewej nerki. Ze względu na niskie wartości ciśnienia (< 100/60 mm Hg) u pacjenta zmniejszono dawkę doksazosyny do 2 razy $2 \mathrm{mg}$ i furosemidu do $40 \mathrm{mg}$ oraz odstawiono wieczorną dawkę klonidyny.

W celu wykluczenia wtórnych przyczyn nadciśnienia tętniczego oraz oceny skuteczności leczenia 2 miesiące po zdarzeniu przyjęto pacjenta do kliniki kardiologii inwazyjnej. W okresie między hospitalizacjami schudł on $13 \mathrm{~kg}$. Przy przyjęciu do kliniki poza nadwagą (wskaźnik masy ciała [BMl, body mass index] $27 \mathrm{~kg} / \mathrm{m}^{2}$ ) nie stwierdzono istotnych odchyleń w badaniu przedmiotowym. W badaniach laboratoryjnych spośród odchyleń wykazano podwyższone parametry niewydolności nerek (stężenie kreatyniny 1,89 mg/ dl, wartość eGFR $39 \mathrm{ml} / \mathrm{min}$ ) i obniżone stężenie $25(\mathrm{OH})$ witaminy $\mathrm{D}(22,3 \mathrm{ng} / \mathrm{ml})$. Zaobserwowano normalizacje parametrów gospodarki lipidowej (stężenie cholesterolu całkowitego $154 \mathrm{mg} / \mathrm{dl}$, stężenie cholesterolu frakcji HDL 
$38 \mathrm{mg} / \mathrm{dl}$, stężenie cholesterolu frakcji LDL $101 \mathrm{mg} / \mathrm{dl}$, stężenie triglicerydów $74 \mathrm{mg} / \mathrm{dl}$ ).

Stwierdzono prawidłowe stężenie aldosteronu, wskaźnik aldosteronowo-reninowy, rytm dobowego kortyzolu oraz wydalanie metoksykatecholamin w dobowej zbiórce moczu. W badaniu echokardiograficznym (ECHO) serca nie zobrazowano cech przerostu lewej komory, odcinkowych zaburzeń kurczliwości ścian lewej komory (frakcja wyrzutowa [EF, ejection fraction] 65\%) i wolnej ściany prawej komory (skurczowy ruch płaszczyzny pierścienia trójdzielnego [TAPSE, tricuspid annular plane systolic excursion] $29 \mathrm{~mm}$ ) ani zaburzeń funkcji rozkurczowej. Z powodu zgłaszanych kołatań serca wykonano badanie EKG metodą Holtera, w którym nie zarejestrowano zaburzeń rytmu i przewodzenia W 24-godzinnym monitorowaniu RR stwierdzono prawidłowe średnie wartości ciśnienia tętniczego z całej doby (114/64 mm Hg), dnia (115/66 mm Hg) i nocy (108/58 mm Hg); nie wykazano fizjologicznego spadku RR w nocy. Średnia poranna wartość ciśnienia wynosiła 132/71 mm Hg. Zmodyfikowano leczenie hipotensyjne odstawiono klonidynę, zalecono pełną dawkę dobową walsartanu (160 mg) na wieczór oraz włączono suplementację witaminy $\mathrm{D}$.

\section{Podsumowanie}

Nadciśnienie tętnicze jest głównym czynnikiem ryzyka wystąpienia rozwarstwienia aorty. W ostrym stanie należy dążyć do obniżenia ciśnienia skurczowego do wartości 100-120 mm Hg [3].

W pierwszym okresie AOD zaleca się dożylne podawanie leków beta-adrenolitycznych. W przypadku przewlekłego rozwarstwienia aorty typu B ciśnienie tętnicze powinno być obniżane do wartości poniżej 130/80 mmHg. Wykazano poprawę przeżycia dzięki stosowaniu beta-adrenolityków oraz antagonistów wapnia. W opisanym przypadku pacjent wymagał podawania kilku leków w celu ustabilizowania RR i tętna w okresach przed-i pooperacyjnym. Podczas hospitalizacji w klinice chirurgii naczyniowej wielokrotnie konieczna była modyfikacja farmakoterapii, ponieważ obserwowano znaczne wahania wartości RR w ciągu doby. Dlatego zastosowany pierwszy schemat leczenia był skomplikowany (łącznie 6 leków hipotensyjnych przyjmowanych $3 \times /$ d.), ale zapewniał całodobowe obniżenie ciśnienia poniżej 120/80 mm Hg. Jednak niezaprzeczalnie jego utrzymanie wiązało się z ryzykiem nieprzestrzegania zaleceń przez pacjenta. Korzystniejsze byłoby dawkowanie niektórych leków raz na dobę (doksazosyna, walsartan, bursztynian zamiast winianu metoprololu) oraz zastosowanie preparatów złożonych, co zresztą wprowadzono podczas kolejnych hospitalizacji. W dalszej obserwacji u pacjenta uzyskano redukcję wartości RR pozwalającą na odstawienie części leków i uproszczenie dawkowania. Oprócz leczenia hipotensyjnego u chorego zastosowano statynę [3].

Ze względu na przewlekłą chorobę nerek z eGFR 30-59 ml/min ryzyko sercowo-naczyniowego u opisywanego pacjenta jest wysokie. W tej grupie osób, w przypadku stężeń cholesterolu frakcji LDL w zakresie 100-154 mg/ dl, zaleca się modyfikację stylu życia oraz interwencje farmakologiczną z docelową wartością cholesterolu frakcji LDL poniżej $100 \mathrm{mg} / \mathrm{dl}$. Za włączeniem do leczenia statyny przemawiają także wyniki małych badań obserwacyjnych sugerujące korzystny wpływ statyn ma hamowanie powiększania się tętniaków.

\section{Konflikt interesów}

Nie zgłoszono.

\section{Abstract}

Acute aortic dissection (AOD) is one of the possible complications of untreated hypertension. Its symptoms (severe popping chest pain radiating to the back) are often confused with acute coronary syndrome. The basis of diagnosis is a computed tomography of the aorta. Patients with AOD requires emergency vascular surgery. One of the conditions for the success and good prognosis is to reduce blood pressure. The paper presents a case of a patient with long-standing untreated hypertension, in whom there was a dissection of the descending aorta and its branches, and consequently the deterioration of renal function. After initial difficulties in determining the optimal pharmacotherapy reduction of blood pressure was achieved and widening gates delamination is not observed.

Key words: hypertension, dyslipidemia, acute aortic dissection

Folia Cardiologica 2017; 12, supl. B: B30-B33

\section{Piśmiennictwo}

1. Erbel R, Aboyans V, Boileau C, et al. [2014 ESC Guidelines on the diagnosis and treatment of aortic diseases]. Kardiola Pol. 2014; 72(12): 1169-1252, doi: 10.5603/kp.2014.0225, indexed in Pubmed: 25524604.
2. Interna Szczeklika. Podręcznik chorób wewnętrznych. Medycyna Praktyczna, Kraków 2015/2016: 819.

3. Tykarski A, Narkiewicz K, Gaciong Z, et al. Zasady postępowania w nadciśnieniu tętni-czym - 2015. Nadciśnienie Tętnicze w Praktyce. 2015; 1(1): 1-70. 